\title{
If You Build It, Will They Consume? Key Challenges for Universal, Reliable, and Low-Cost Electricity Delivery in Kenya
}

\section{Jay Taneja}

\section{Abstract}

Kenya's rapid electrification in the past decade has improved the lives of millions, and can serve as a template for other countries that are growing their electricity systems and coverage. However, significant challenges remain: many more remain without access, there is low consumption among those that are connected, and the electricity supply has poor reliability and quality. This paper provides analysis that shows electrification can be improved by considering cheaper options that still meet the needs of low consumers and that low consumption is a first-order problem for the sustainability of utilities.

\section{Working Paper 491 July 2018}




\title{
If You Build It, Will They Consume? Key Challenges for Universal, Reliable, and Low-Cost Electricity Delivery in Kenya
}

\author{
Jay Taneja \\ STIMA Lab, University of Massachusetts - Amherst and \\ Energy for Growth Hub
}

The Center for Global Development is grateful for contributions from the Rockefeller Foundation and the Pritzker Innovation Fund in support of this work.

Jay Taneja, 2018. "If You Build It, Will They Consume? Key Challenges for Universal, Reliable, and Low-Cost Electricity Delivery in Kenya.” CGD Working Paper 491.

Washington, DC: Center for Global Development. https://www.cgdev.org/publication/ if-you-build-it-will-they-consume-key-challenges-universal-reliable-and-low-cost

Center for Global Development 2055 L Street NW Washington, DC 20036

202.416 .4000

(f) 202.416 .4050

www.cgdev.org
The Center for Global Development works to reduce global poverty and improve lives through innovative economic research that drives better policy and practice by the world's top decision makers. Use and dissemination of this Working Paper is encouraged; however, reproduced copies may not be used for commercial purposes. Further usage is permitted under the terms of the Creative Commons License.

The views expressed in CGD Working Papers are those of the authors and should not be attributed to the board of directors, funders of the Center for Global Development, or the authors' respective organizations. 


\section{Preface}

CGD's work on energy has focused principally on definitions of energy access, data analysis, and the efficacy of international tools available to spur investment in the power sector in emerging economies. Kenya's experience with electrification has been among the most fascinating, with a recent campaign by the government to aggressively add grid connections. This push is designed to bring benefits to millions of Kenyan households, yet it also comes with implications for the entire power system. To better understand Kenya's electricity situation and policy options, we commissioned this terrific paper from Jay Taneja of the Systems Towards Infrastructure Monitoring and Analytics (STIMA) Lab in the Department of Electrical and Computer Engineering at the University of Massachusetts - Amherst. Taneja also spent four years leading an energy team at the IBM Research Lab in Nairobi. His paper provides analysis showing that low consumption is a first-order problem for the sustainability of utilities and argues that electrification can be improved by considering cheaper options that still meet the needs of low consumers.

Todd Moss

Senior Fellow

Center for Global Development 


\section{Executive Summary}

This paper presents the key challenges faced in providing universal, reliable, and low-cost electricity in Kenya. While the paper focuses on Kenya, many of the lessons highlighted are relevant for other countries in sub-Saharan Africa, many of which have limited grid footprints and are confronting the challenges of increasing electrification while sorting through the enormous changes in technology, policy, and financial options presented by recent developments.

The Government of Kenya, the international finance community, private enterprises, and non-governmental organizations have driven massive improvements in electricity access for Kenya's citizens; electrification has grown from $20 \%$ to well over $50 \%$ within the last decade, and rapid growth continues. However, there remains substantial room for improvement, as large numbers of households still do not have electricity connections, many newly-connected customers only consume limited amounts of electricity, and economic growth is stifled by poor reliability and quality of electric supply. This paper examines key questions on these topics and more, providing background and analysis using data gathered from Kenya Power and other sources. In particular, we find that:

- The high cost of providing grid electricity connections does not necessarily justify the benefits derived by newly-connected grid customers. Energy system planners should explore alternative means of electrification, including solar home systems and minigrids, which both can meet the projected electricity needs of many of the presently-unconnected households at a fraction of the cost of the centralized electricity grid.

- Low consumption among newly-electrified customers should be a critical concern for the utility and government. Without improving consumption density, rural areas are likely to remain poorly-developed, limiting human and economic development. Governments and the utility should focus on actively enabling positive electricity consumption habits, developing rural enterprises, and improving system reliability to build customer confidence in electricity supplies. Simply providing access to electricity has not proven to be enough to catalyze rural development; a more holistic approach is needed.

- Planning should depend on reasonable electricity demand growth projections that are produced by parties without incentives to overstate growth. Overly rosy projections could lead to "white elephant" projects, particularly for power generation. These types of projects not only result in wasted electricity capacity, but also drive up the price of electricity for consumers as well as businesses. At the same time, planning for some level of growth is essential, so responsibly projecting both where and among whom that growth is likely to occur should also drive the planning process. 


\section{Background and Kenya's Electricity Sector}

Advances in electricity technology, energy systems planning, and donor and multilateral financing have led to dynamic growth in electricity systems across sub-Saharan Africa. Previously, to increase electricity access, governments could only access limited sources for the large debt needed to finance grid extension, and little was understood about the expected success of those investments. Now, a groundswell of new energy technologies - distributed generation, smart and prepaid metering, energy storage, and predictive analytics - are enabling better planning of a diverse array of systems for providing reliable electricity to the growing communities throughout the continent, attracting more and varied financing. Kenya, as a lower-middle income country with a strong penchant for technology adoption - highlighted by the broad adoption of a mobile money system - stands at the vanguard of a new era, serving as a testing ground for a wide range of new technologies, business models, and financing strategies that are charting a new course for electricity delivery in sub-Saharan Africa.

However, despite the vast gains already achieved by recent electrification efforts, Kenya faces persistent challenges as it seeks to meet the goals of universal electrification laid out in UN Sustainable Development Goal \#7. This paper provides a data-driven analysis of three challenges facing policymakers, electricity service providers, investors, and donors seeking to build a replicable model for powering economies on the continent to grow incomes and improve outcomes. In particular, these challenges are:

- Balancing Access and Profitability. With more than only the national utility now providing electricity service, how can government ensure electricity access for all while also ensuring that investors receive healthy returns from service providers?

- Stimulating Demand for Electricity. As a larger share of the population gains access to electricity, how can providers ensure that these newlyminted customers grow their consumption, empowering customers to derive the full benefits of access while ensuring that service providers can continue to grow their footprints? In addition, how does this challenge differ for industrial, commercial, and residential customers?

- Matching Infrastructure to Expected Demand. How can new and improved electricity system planning tools enable service providers and policymakers to deploy electricity systems built for expected growth?

While we discuss these challenges in the context of Kenya, they are also relevant in many other countries and regions. The large investments by international finance institutions, the government of Kenya, and venture capitalists into reforming and expanding the electricity system in Kenya are helping to develop a list of best practices for improving access and reliability of electricity in low-income countries in the age of centralized and distributed generation. Collectively, we are learning what does and does not work for achieving universal access to reliable and plentiful electricity given modern circumstances. 
Kenya's Electricity Sector. Similar to many other low-income countries, the electricity sector in Kenya is reforming after recent deregulation. Figure 1 depicts the major stakeholders involved in the sector, which now incorporates competitive aspects in the generation market. At present, roughly $2 / 3$ of generation capacity is owned by the legacy generator, KenGen, with the remaining $1 / 3$ owned by Independent Power Producers (IPPs). A thorough history of IPP participation in Kenya can be found in a recent book on the topic [12. Transmission is owned and operated by the regulated Kenya Transmission Company (KETRACO), which is 70\% government-owned and 30\% investor-owned. Distribution on the central grid is the sole responsibility of the national utility, Kenya Power, with a current customer base of over 6.1 million. Kenya Power is $50.1 \%$ government-owned and $49.9 \%$ investor-owned.

Figure 1. Stakeholders in the electricity sector in Kenya. Government bodies provide oversight at multiple tiers in the sector.

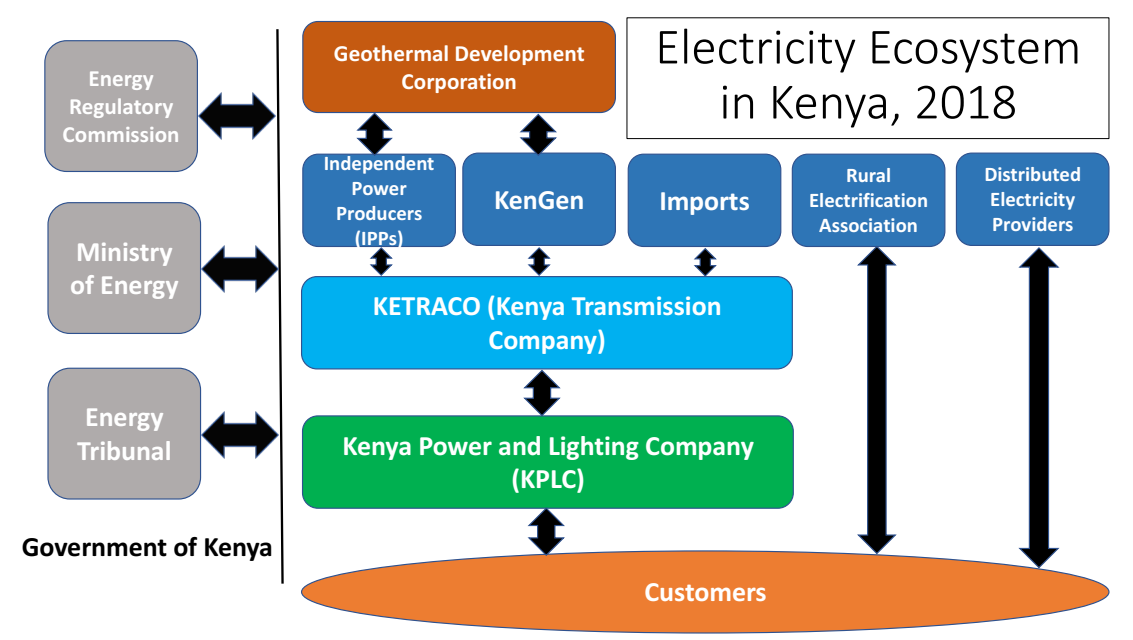

The generation mix in Kenya is almost entirely composed of three types of generation: hydroelectric, geothermal, and diesel, with a nominal wind generation facility as well. A breakdown of energy generation by percentage and by average power is available in Figure 2 In the last three years, enormous increases in available geothermal energy have driven a massive increase in available capacity and a reduction in the cost and price of electricity. Also evident is the susceptibility of Kenya's electricity supply to drought periods, where imported diesel and emergency generation are used to deal with shortfalls in expected 
supply. Nonetheless, unlike many other countries on the continent, Kenya does not suffer from shortfalls in available generation; the country is in fact demandlimited while many others are supply-limited. This alone helps the country to be among the stronger economies on the continent.

Figure 2. Local electricity generation in Kenya (a.) by percentage and (b.) by average power. Data are from the Kenya National Bureau of Statistics [4].

(a) Generation by Percentage

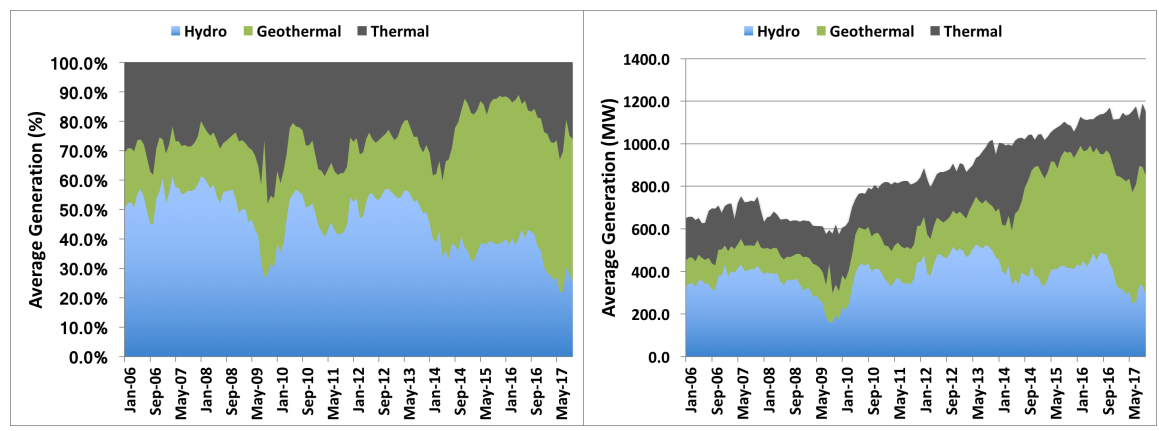

A map of Kenya's population density is provided in Figure 3 . However, as in many countries, electricity consumption is not divided proportionally among the population. Electricity demand in the country is concentrated in the capital region; Nairobi and its metropolitan area, with a population of approximately 4 million out of a national population of an estimated 50 million, is responsible for $47 \%$ of total electricity sales by the utility [16. The Coast region, anchored by Kenya's second city and principal port Mombasa, is responsible for another $17 \%$ of consumption. At the time of writing, the most recent estimates of electrification from the utility claim that $70.3 \%$ of the population is connected to the grid, though there may be reason to doubt the veracity of connection numbers reported by the utility [6. In any case, the vast majority of customers with electricity connections consume only small amounts, barely registering in national totals. As Kenya rapidly electrifies, this paper discusses some challenges to the approaches being undertaken and presents some strategies to more costeffectively address the inequities in Kenya's electricity system.

\section{Balancing Access vs. Profitability}

One of the most salient challenges facing electricity grid planners in Kenya is the structure of the national utility, Kenya Power. In an effort to improve the efficiency and financial stability of the organization, the Government of Kenya and the World Bank pushed for a series of market reforms in the 1990s and 2000s, chief among them the break up of the monolithic, vertically-integrated electricity 
Figure 3. Population density in Kenya. Each dot represents 100 people [14].

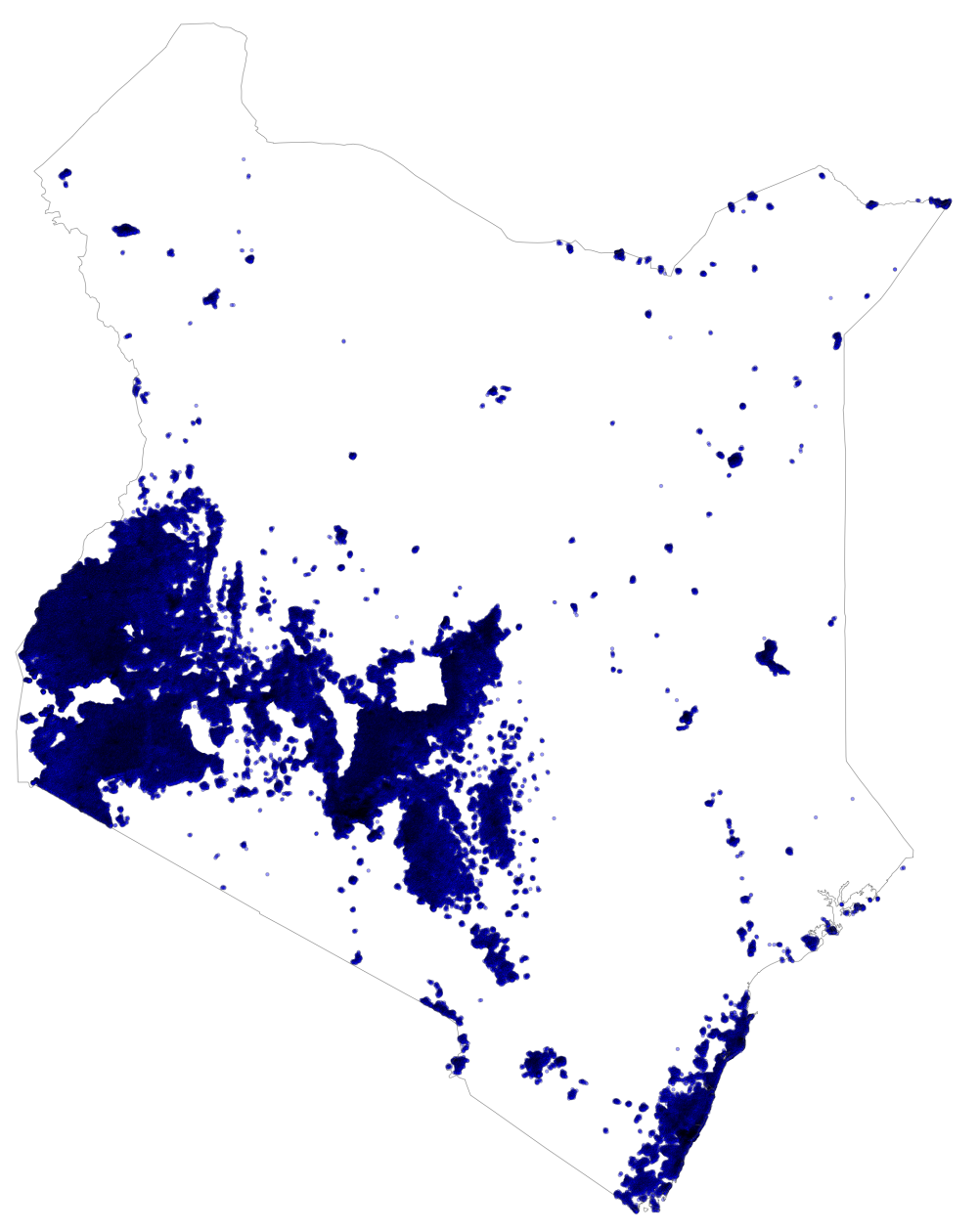


provider and the deregulation of the electricity generation market. Additionally, and pivotally, the national utility was partially privatized; presently, $49.9 \%$ of the utility is investor-owned and listed on the Nairobi Stock Exchange, while $50.1 \%$ of the utility remains owned by the Government of Kenya (GoK). This split ownership effectively creates a 'dual mandate' for Kenya Power: investors demand profits and growth while government seeks universal access to lowcost electricity. Unfortunately, this dual mandate, coupled with technological developments and their resulting market forces, poses an existential threat to the utility.

Figure 4 shows the rapid growth in the residential customer base of Kenya Power since 2010 [14. This massive expansion of the central grid is motivated by the GoK's electrification goals of $70 \%$ by $201 \gamma^{1}$ and universal electrification by 2020 .

Figure 4. Number of customers and electricity sales for Kenya Power [16].
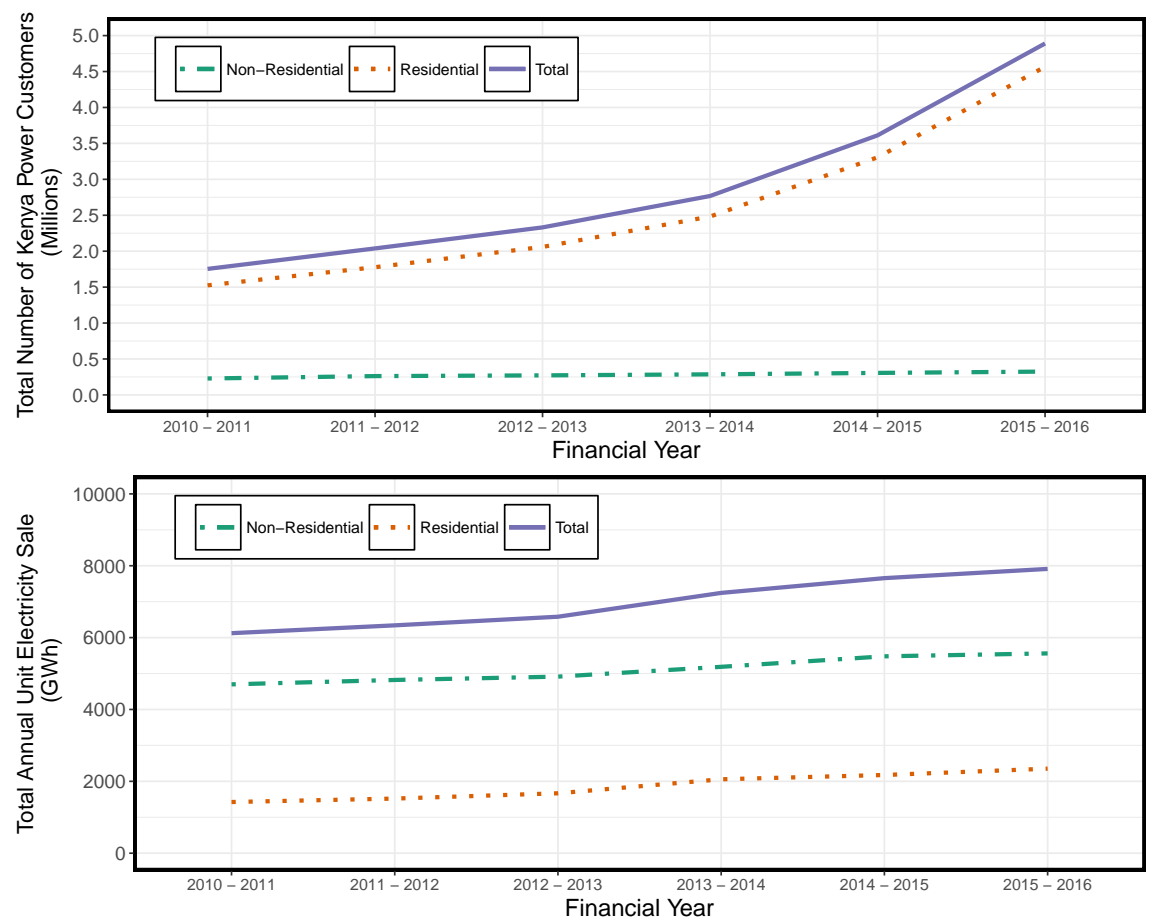

At the same time, the consumption levels of new customers is different from older ones; Figure 5 shows the change in average consumption for each customer class in Kenya. From the figure, we can see that the average residential

\footnotetext{
${ }^{1}$ GoK claims to have met this target, though there are doubts about the veracity of the numbers supporting this claim 6].
} 
Figure 5. Electricity consumption per customer in Kenya. Data are from the Kenya Power annual reports [16].

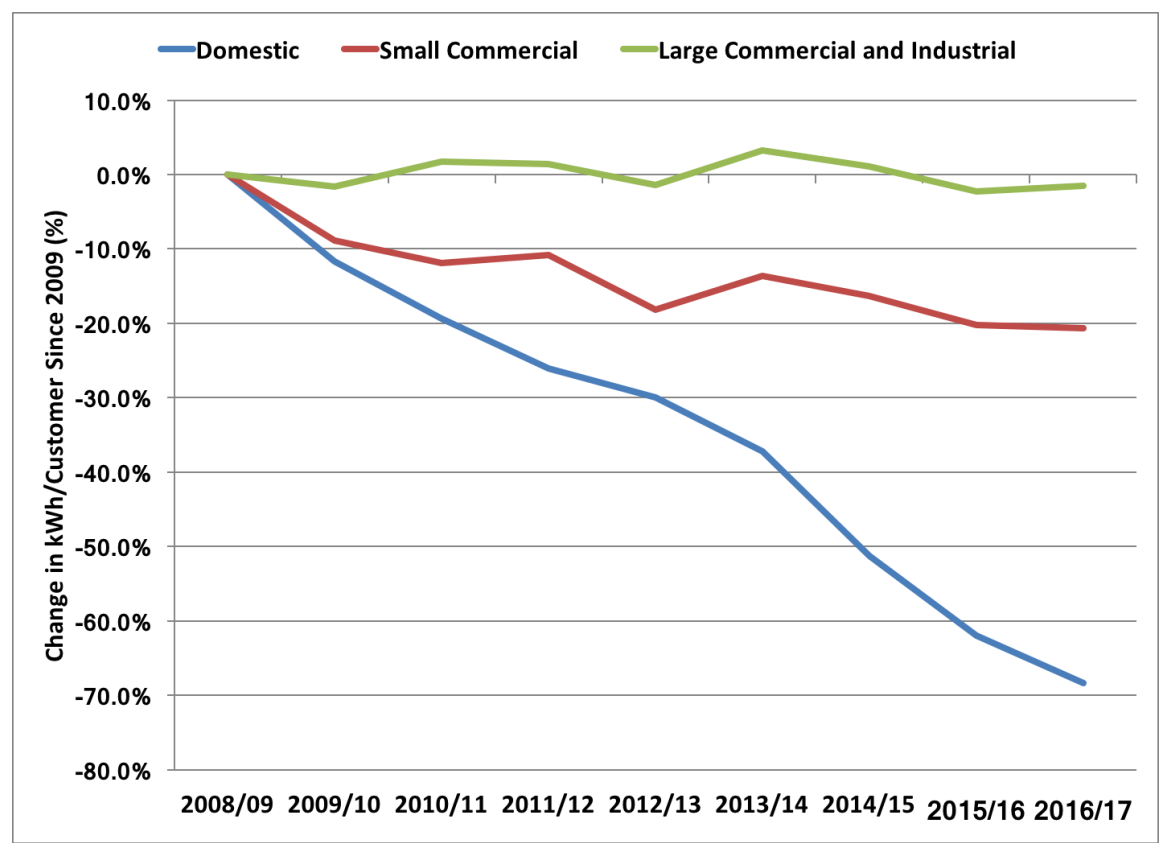

customer now consumes only $30 \%$ of the electricity that the average residential customer consumed in 2009. One argument is that the breakneck pace of growth is tipping the balance of residential customers towards households that are newly-electrified and lower-consuming. A deeper look at this troubling trend can be seen in Figure 6, which shows the median residential monthly consumption of a large sample of rural and urban residential customers in Kenya from time of connection [14. Here we can see how consumption develops - initially, there is aggressive growth, which soon subsides to a peak level of consumption. What is changing with newer customers is at what level consumption peaks and how quickly that peak occurs. It is important to note that in this graph, we are observing median customers instead of average customers, but also that we are observing consumption levels for only customers with postpaid meters. Previous work from South Africa has shown 12-15\% reductions in consumption when customers switch from postpaid meters to prepaid meters [15.

In total, as the average revenue per customer decreases, the utility faces an increasingly difficult situation. This situation is compounded by the high costs of connecting new customers. Three reports provide sample costs of connections:

- Parshall, et al. estimate the average cost to the utility of $\$ 1900$ per connection 21.

- A consulting report commissioned by the GoK showed an average cost of 
$\$ 1400$ per connection, with an estimate that $70 \%$ of the cost is due to materials (wires and poles) [13].

- The Rural Electric Power Project (REPP) from UC Berkeley collected a sample of cost data from 77 connection projects in Western Kenya, finding an average cost of $\$ 1813$ per connection - see Figure 7 for a figure attempting to derive a model for connection cost as a function of community coverage [20].

Figure 6. Growth in electricity consumption among (a.) rural customers and (b.) urban customers [14].

(a) Rural Customers

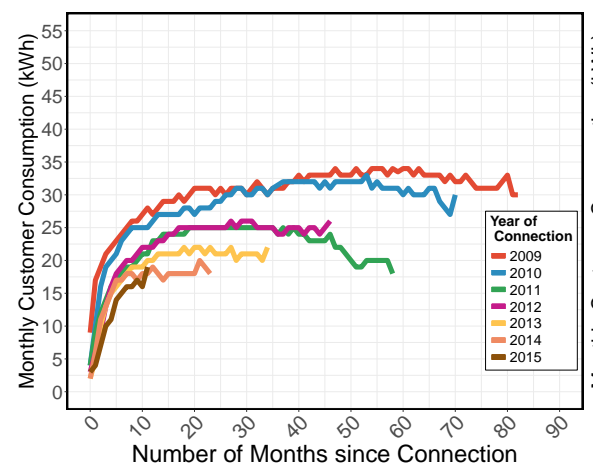

(b) Urban/Peri-Urban Customers

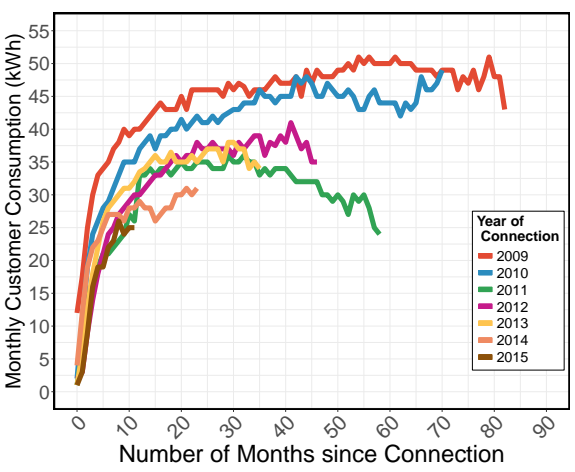

Recognizing that this high cost is beyond the means of the consumer getting connected, utilities typically charge a flat connection fee for any customer within range of existing instrumentation; in Kenya, any customer within 600 meters of a transformer can connect at a flat price of $\$ 350$. However, even this fee is too expensive for many rural customers; in an effort to understand the implications of this, the Berkeley REPP team conducted a willingness-to-pay study on the cost of connections in Western Kenya, finding the take-up curve shown in Figure 8 20. This curve shows that take-up of connections was less than anyone - the GoK or the researchers - predicted. In an effort to make new electricity connections more accessible to consumers, the GoK instituted a plan as part of its Last Mile Connectivity Program to reduce the connection fee to $\$ 150$; however, at this price, take-up in the REPP study was roughly one-third of what government had predicted. At the time of Kenya Power's most recent annual report (June 30th, 2017), only roughly 50k customers had been connected as part of the Last Mile Connectivity Program, though many others had been connected via other programs [16].

In addition to grids, electricity system planners can now leverage the unique capabilities afforded by distributed electricity systems like minigrids and solar home systems for increasing energy access. The promise of these systems is to provide lower-cost electricity by taking advantage of rapidly improving 
Figure 7. Cost of connections in Kenya vs. community coverage. From the Rural Electric Power Project at UC Berkeley [20].

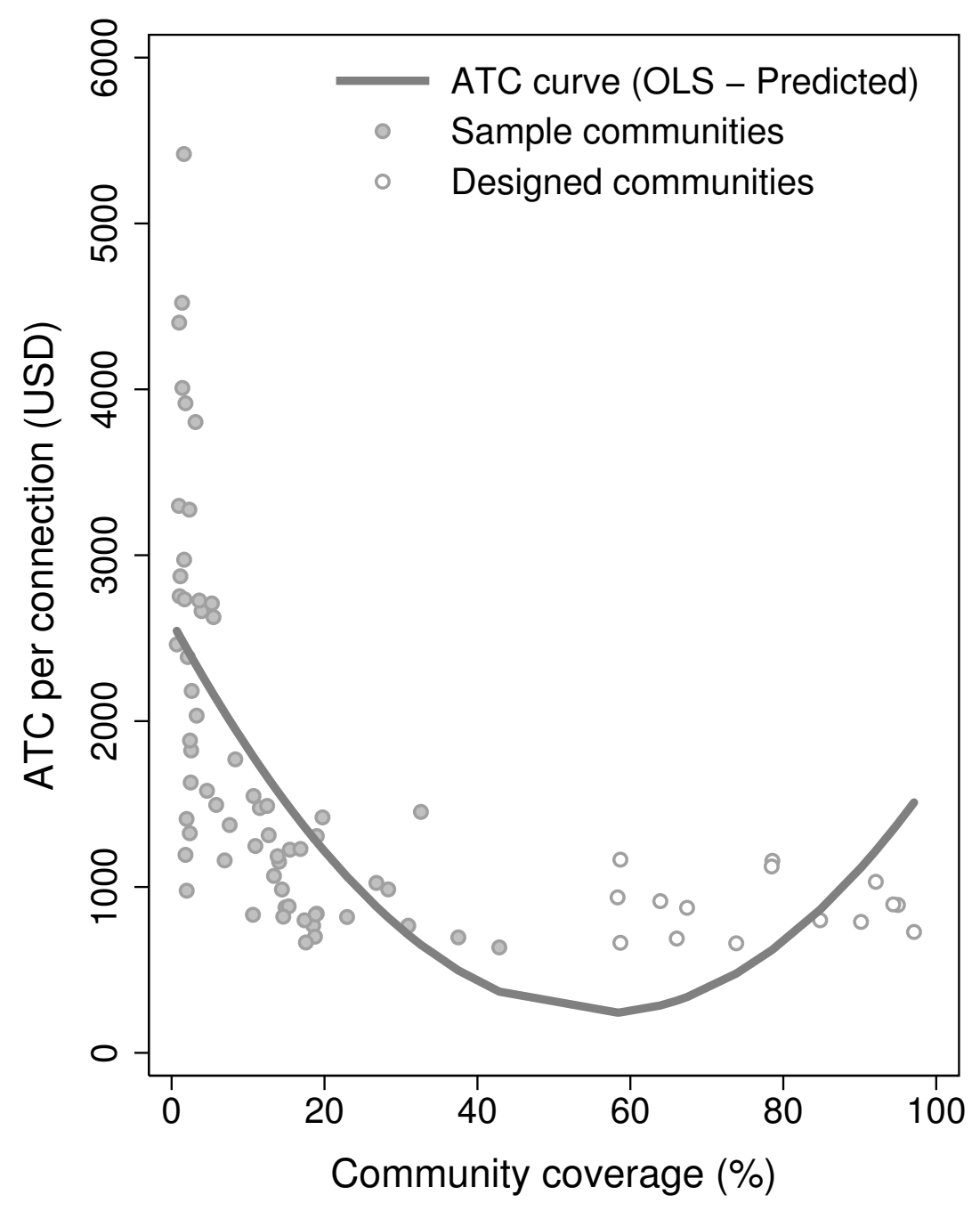


Figure 8. Take up for electricity connection offers in rural Kenya. From the Rural Electric Power Project at UC Berkeley [20].

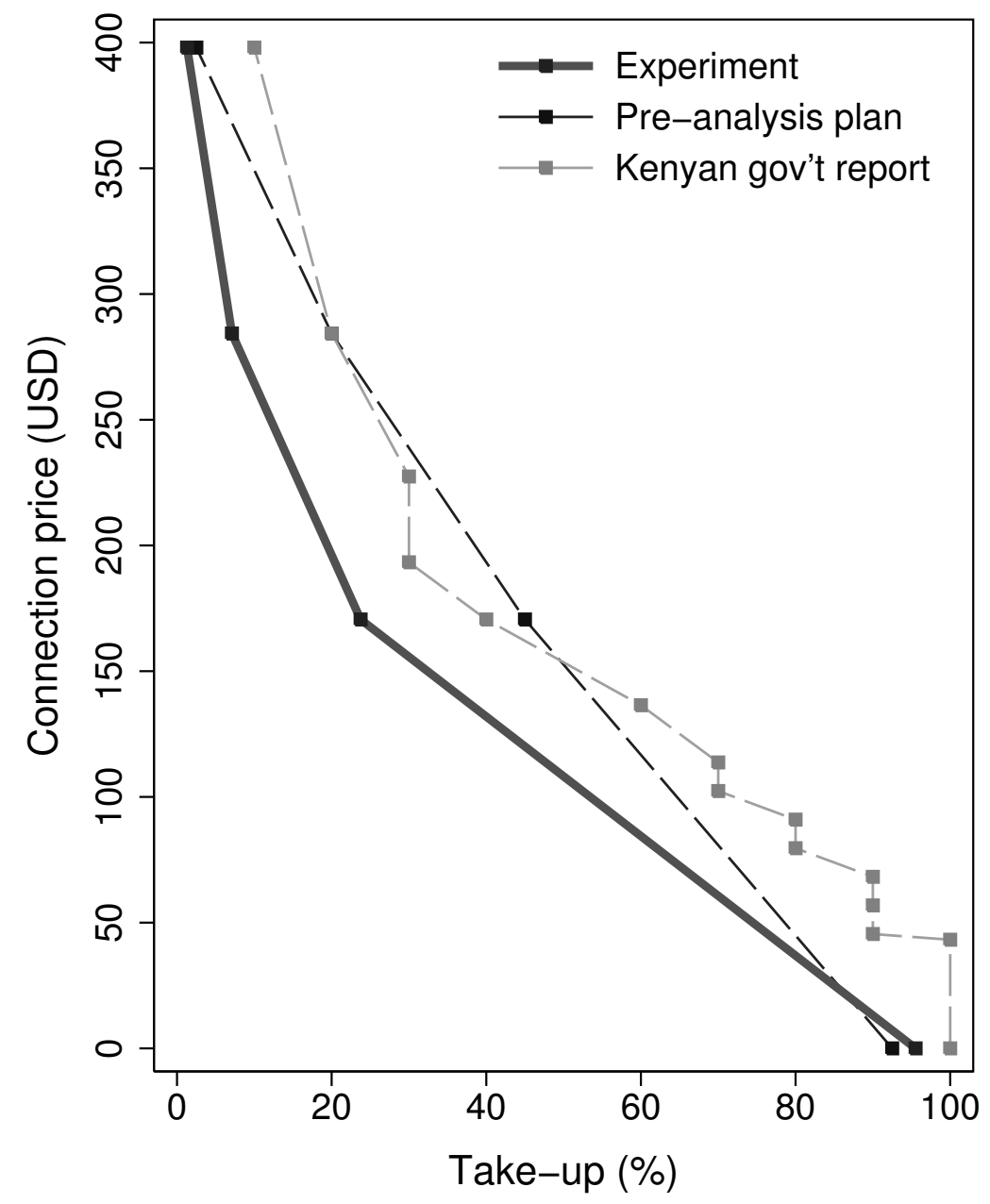


distributed generation that does not need interconnection with the centralized electricity grid. Further, these systems can be privately- or community-owned, reducing dependence on the national utility as the sole source of electricity access.

In Kenya, solar home systems are of particular noteworthiness - there are roughly 40 privately-owned solar home system providers; while accurate estimates of total deployments are not widely available, current deployments are likely over half a million systems deployed in Kenya, increasing total electrification across the country by $5 \%$. Minigrids, on the other hand, are not nearly as mature in Kenya, with a relatively small number of systems (on the order of 100, serving on the order of 10k households) deployed, with many owned by not-for-profit entities, often as demonstration systems. One advantage held by both of these types of systems is that their costs continue to drop - while solar panels have become much cheaper over the last decade, balance-of-system and energy storage costs still have substantial room for reduction. Unfortunately, centralized grids do not have the same cost reductions on the horizon. We discuss how these innovations can be used for better infrastructure planning in Section 4 .

\section{$3 \quad$ Stimulating Demand for Electricity}

Another critical challenge for electricity delivery in Kenya is to ensure healthy growth of consumption among customers. Though causality between electricity consumption and economic growth remains undetermined, it has been shown that low electricity consumption correlates with lower gross domestic product, lower human development index, and a host of other indicators. What may be changing is the level of consumption that constitutes sufficient - changes in lifestyle due to new technology, improved appliance efficiency, and the forces of globalization make it less clear exactly how much consumption is necessary for higher standards of living and to fuel economic growth at different income levels. While the evidence that rural electrification has substantial impact on incomes is highly equivocal [8, 10, 11], most would agree that Kenya, at roughly 200 $\mathrm{kWh} /$ person/year, would benefit from higher aggregate electricity consumption.

Another key benefit of higher consumption is to improve the financial sustainability of the electricity utility. Figure 9 is from a study conducted by a team at the World Bank that looked at the balance sheets of utilities across sub-Saharan Africa, finding that (1) electricity is more expensive on the continent than any other region; (2) most utilities in sub-Saharan Africa cannot meet their operating expenses with current revenues and collections; and (3) only two of the utilities profiled (Uganda and the Seychelles) can meet their total operating and capital expenses [18. While Kenya Power is in a relatively better financial position than its peers, it still requires large loans to meet its capital expenditures and has significant room for improvement of its financial health.

From Figures 5 and 6 , we are able to infer a trajectory for the future of 
Figure 9. Financial health of electricity utilities in sub-Saharan Africa [18].

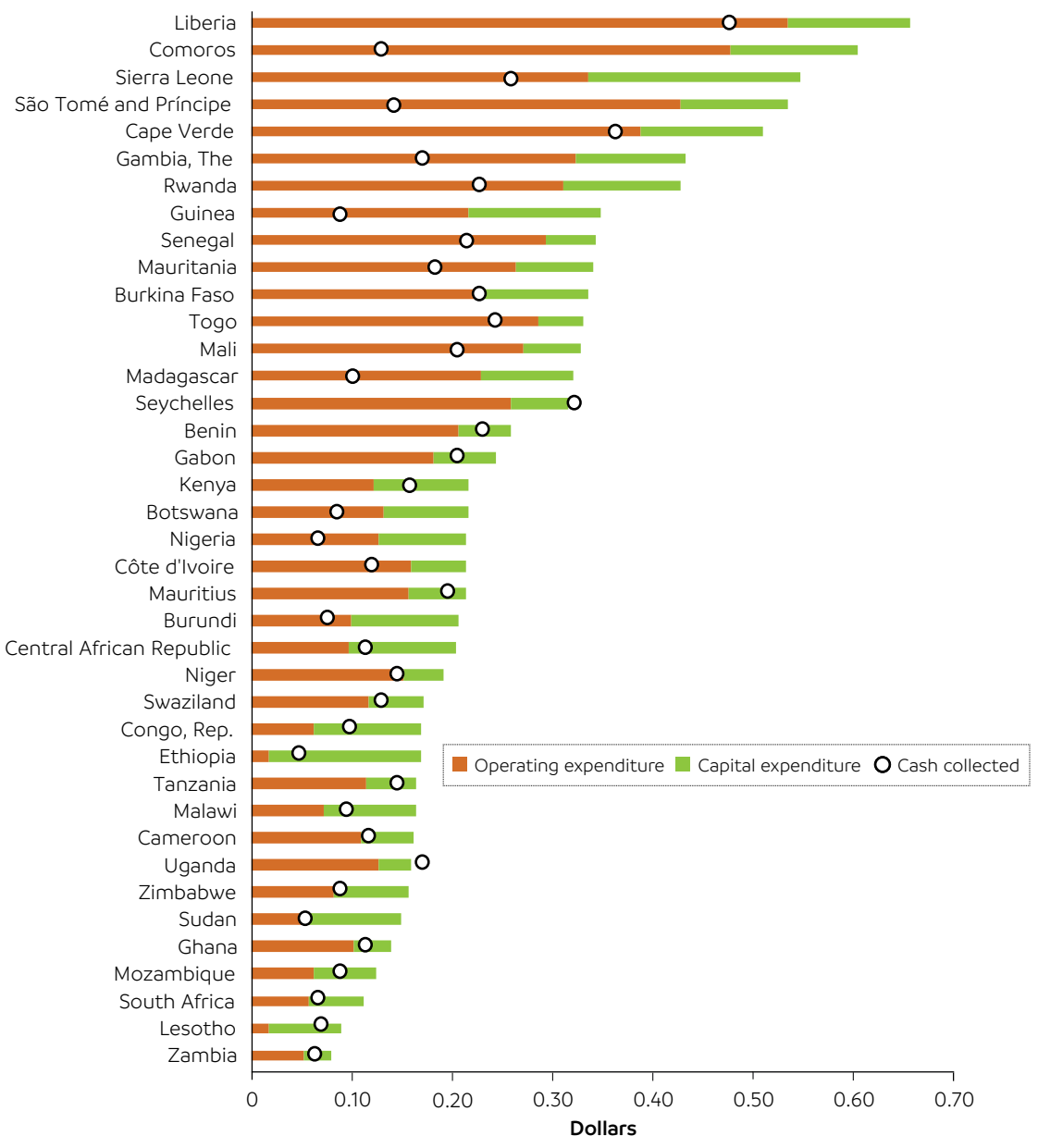


electricity consumption among residential customers in Kenya. This businessas-usual trajectory presents an enormous challenge to the utility: extending the grid to increasingly poorer customers results in reduced revenue per customer. Yet, costs scale in the opposite direction - as revenues per customer are reduced, costs for connecting these customers grow, as these customers are further afield. Then, multiple questions arise: how can Kenya Power help these newly-connected customers grow their consumption? Is this a reasonable extension of a utility's role? Further, we note that demand stimulation is a critical challenge for all electricity service providers in Kenya; minigrid operators also cannot meet their costs with the low consumption currently used by their customers, and solar home system vendors are attempting to push customers up the consumption ladder, aiming to sell more expensive and higher-consuming appliances.

Towards this end, we will briefly discuss three pathways for improving electricity consumption in Kenya:

- Enabling rural customers to develop positive electricity habits

- Developing local enterprises

- Improving system reliability to build confidence in electricity delivery

Enabling positive electricity habits. As a first step, it is important to better understand the drivers of consumption among rural consumers. Again, the Berkeley REPP team provides insight - Figure 10 shows ownership and desired ownership of appliances among three different groups of consumers: those with a grid connection to electricity, those with solar home systems, and those that primarily use kerosene for lighting [19. While we see large differences among these three cohorts, we also see a significant gap between desired ownership and actual ownership. Improving access to financing and supply chains for appliances is likely to yield increased electricity consumption, though design of effective programs remains an open question.

Another aspect that is likely to uncover latent demand is educational. As Samuel Insull learned when he built Chicago Edison into a modern electricity utility in the early 20th century, customers must weave consumption into the fabric of their lives. Insull slashed the price of electricity to encourage residential consumption and motivate industrial consumers to consume at night to make better use of otherwise idle generation capacity. While this approach may have few benefits for Kenya Power, the received wisdom of how to build a utility may be beneficial to minigrid operators. However, behavior change is never easy, and the best methods to encourage an electricity habit among consumers remains a ripe area for research.

Developing local enterprises. Many of the same insights from residential customers hold true for commercial and industrial consumers. In rural areas, these customers can benefit from better access appliances but can also gain from business model support. The consumption growth trajectories shown in this work provide evidence that the business-as-usual approach of "if you build 
Figure 10. Owned and desired appliances among households in Western Kenya among three groups with different lighting sources: gridconnected, solar home system, and kerosene [19].
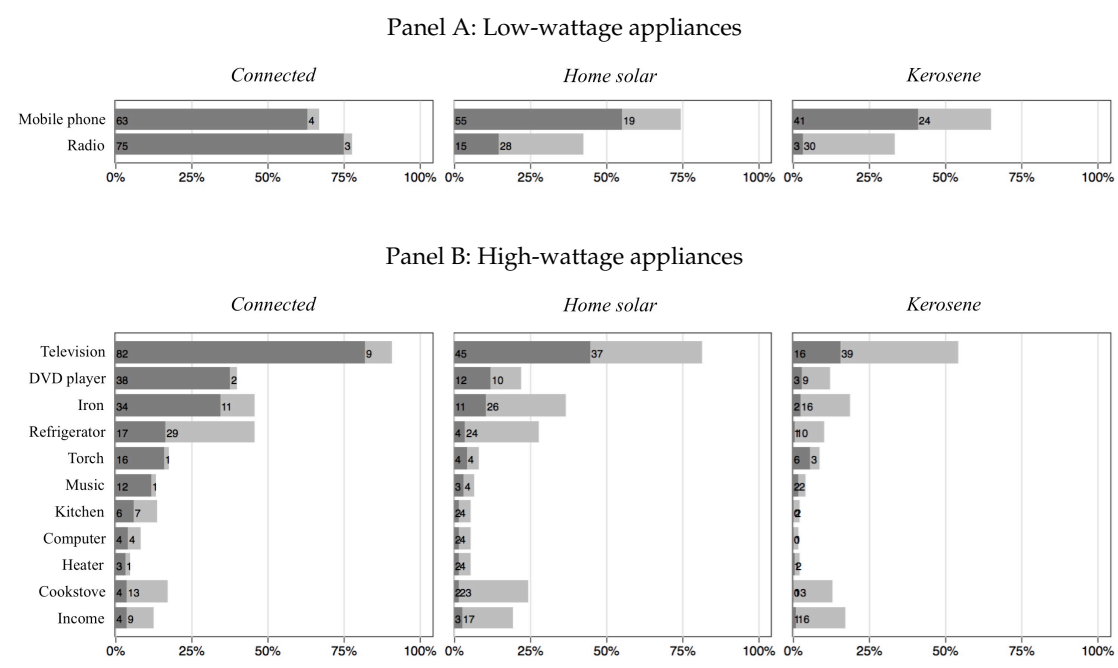

Owned appliance $\square$ Desired appliance

it, they will consume" does not encourage enough growth among these customer classes.

Among existing industrial customers, another challenge is emerging. These customers are critical to the success of Kenya Power's revenue base - Table 1 shows how the relatively small number of industrial customers $(3,686$ out of over 6.1 million) comprise an outsize portion of total electricity consumption (55.4\%). Maintaining high consumption among this cadre is critical for the utility's survival. While per customer consumption among industrial customers has remained remarkably flat (see Figure 5), the emergence of distributed generation sources has emerged as a threat. For example, some sugar processing plants and tea factories have built self-generation facilities, replacing what would have been revenue-building consumption for the utility. Additionally, large-scale commercial customers are adopting photovoltaic generation - for example, a large new mall in Kenya has outfitted its parking lot with solar panels 2. Obviously, these patterns of growth in distributed generation are being felt by utilities all over the world, but utilities in places like Kenya are especially susceptible, as a larger proportion of overall consumption arises from a relatively small number of industrial customers as compared to industrialized countries.

Improving system reliability. Outages frequently interrupt the lives of electricity users in sub-Saharan Africa - small business owners like merchants and tailors cannot operate effectively without lights or machines, schoolchildren must complete their homework by the flickering lights of candles or kerosene lamps, 
Table 1. Data on customers of Kenya Power in each class, from Kenya Power's annual report for 2016/17 [16]. The balance of consumption is for interruptible and streetlighting loads.

\begin{tabular}{cccc}
\hline Class & $\begin{array}{c}\text { Number of } \\
\text { Customers }\end{array}$ & $\begin{array}{c}\text { \% of Customer } \\
\text { Base }\end{array}$ & $\begin{array}{c}\% \text { of } \\
\text { Consumption }\end{array}$ \\
\hline Domestic & $5,839,865$ & $94.6 \%$ & $27.8 \%$ \\
Small Commercial & 328,576 & $5.3 \%$ & $15.6 \%$ \\
Large Commercial \& Industrial & 3,686 & $0.06 \%$ & $55.4 \%$ \\
\hline
\end{tabular}

and factory workers must scramble to maintain production lines. While the richer among these can use high-cost generators and inverters to cope with outages, the poorer must wait until power is restored, often many hours later.

As a response to unreliability, many customers often "stack" energy sources. For example, roughly one-third of M-KOPA [7] solar home system customers in Kenya also have a grid connection, incurring redundant fees for two different electricity systems. While an unreliable grid makes this strategy rational, it drains the scarce resources of these customers. Improving grid reliability empowers these customers to depend on cheaper grid electricity, which is onefifteenth $(1 / 15 \mathrm{th})$ the per-unit cost of M-KOPA electricity ${ }^{2}$ Additionally, improved reliability enables opportunities for economic growth and quality-of-life improvements for residential customers and bolsters often-underdeveloped small businesses by enabling cost-effective production, improving local economies.

At the same time, Kenya Power is also struggling - to keep the lights on. Each year, Nairobi suffers from 90,000 electricity grid outages, not only hindering the community's economic growth but also costing the utility $\$ 25-40 \mathrm{mil}$ USD in Nairobi alone. While Kenya Power has made great strides over the last decade to supply adequate electricity generation and eliminate rolling blackouts, unplanned outages persist due to poor repair and maintenance practices, outdated equipment, and dynamic growth and urbanization. Figure 11 shows the time of day of electricity outage reporting and repair; while customers cope with outages all day long, the peak consumption hours in the morning and evening provide the most frequent outages, compounding the deleterious effects of electricity outages on customers. Though data are scant for rural customers, they are likely to endure far longer outages; the Berkeley REPP team reported long-term transformer outages on 29 out of 150 of the transformers in their study, with an average outage duration of four months in these communities (for a complete list, see Table A8 in their work [20]). Both persistent as well as long-term outages reduce trust in grid electricity, pushing customers to either find other sources of electricity or to maintain a lifestyle without modern energy sources. While Kenya Power is attempting to address these outages under the mantle of "loss reduction," the utility has limited measurement of outage patterns, especially in rural areas, and next to zero insight on power quality issues

\footnotetext{
${ }^{2}$ This calculation uses assumptions of a five-year replacement time for the SHS, a 25-year amortization of the grid connection cost, and current fee structures for both systems.
} 
that can plague rural areas that have weak electricity infrastructure. However, it is often uneconomical to address these problems that are more prominent in rural areas. Better and cheaper measurement and response to electricity reliability and power quality events is a critical area for research, and without improvement, will continue to hinder the growth of electricity consumption in Kenya and elsewhere in the region. Solar home systems can also suffer from reliability issues; BBOXX catalogs the consistent incidence of "flat battery events" arising from heavy demand on their systems 9 .

Figure 11. Electricity outages in Nairobi by time of day based on one year of data from Kenya Power from October, 2014 - September, 2015.

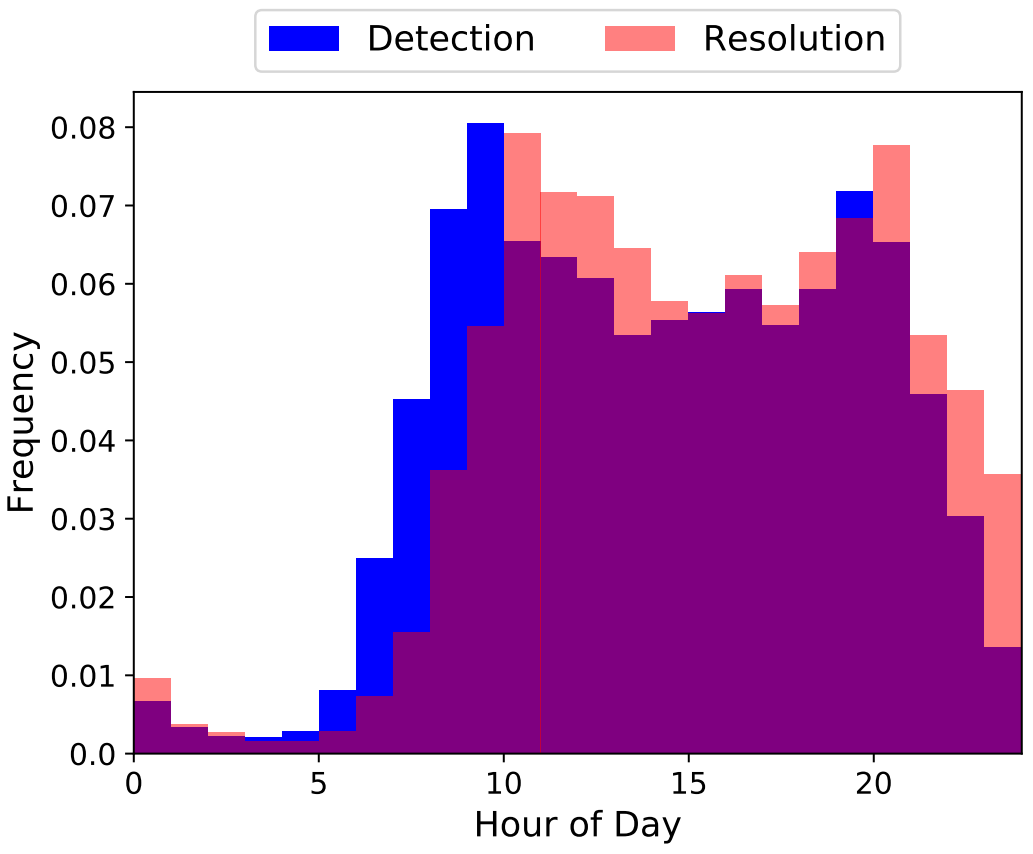

\section{Matching Infrastructure to Expected Demand}

The third challenge we highlight in this work deals with efficient allocation of scarce resources; namely, how can electricity planners ensure that the needs of consumers are met while minimizing the cost of delivering electricity both now and in the future? As noted previously, the advent of different technologies presents electricity planners and policymakers with more options to provide electricity access. While planners and policymakers in Kenya have shown some flexibility in this direction, there remains significant areas for improvement adopting better planning tools, using data-driven projections of future electricity 
consumption, and considering the full slate of technology and business options at their disposal.

The recent history and proclamations of Kenya's government related to adding electricity generation have been misguided. As an election promise in the 2013 campaign, the current administration espoused a plan to add $5000 \mathrm{MW}$ of generation capacity in 40 months. At the time, as can be seen in Figure 12 , Kenya had a total of approximately $1600 \mathrm{MW}$ of total capacity. Thus, the government had proposed to quadruple capacity, but provided few concrete plans to concurrently increase electricity consumption. While market forces seem to have won out and eliminated this target for government 1, vestigial projects that were part of the initial $5000 \mathrm{MW}$ pledge remain. Among these are a plan to install a $1000 \mathrm{MW}$ coal facility in Lamu and to build significant nuclear generation capacity in Kenya. However, insufficient growth in demand coupled renders these as "white elephant" projects, unlikely to prevent any shortages and likely to raise the cost of electricity. Nonetheless, steps have been taken to move forward with these projects, and expensive contracts with questionable clauses and participants await signatures [5. Further, neighboring countries such as Ethiopia and Uganda are adding significant low-cost hydroelectric capacity; it is not possible for everyone in the region to be a net exporter of electricity, and Kenya would do well to recognize this and import this cheap generation rather than build its own ill-advised projects.

Figure 12. Electricity generation, average demand, and peak demand in Kenya. Data are from Kenya Power annual reports [16].

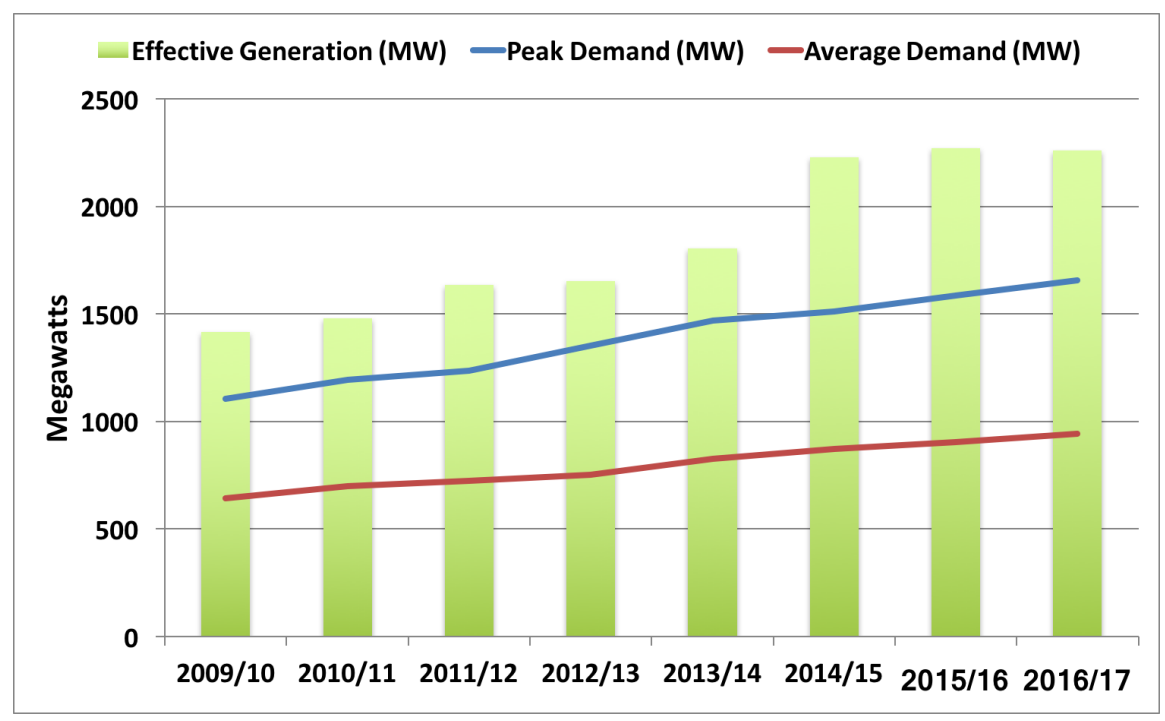

Another area of generation that has been challenging has been wind development. Recently, a large wind generation facility was built at Lake Turkana, an isolated region with enormous wind potential but limited existing infrastructure. 
While the full 310 MW of generation was completed in May, 2017, the transmission authority KETRACO has yet to complete the necessary transmission lines to connect this generation to the main grid, though it is by contract already paying for the electricity that would have been generated, integrated into the main grid, and consumed [3]. This delay, emblematic of poor governance, is unnecessarily driving up the cost of electricity.

Another area of concern is the growing cost of maintenance on the electricity grid. While the GoK has received significant assistance in the form of grants and loans for capital projects - primarily grid extension and transformer densification - we do not know of any loans or grants for offsetting the resulting higher cost of maintenance and repair of a more dispersed electricity grid. As the utility strives to meet ambitious electricity goals set by the GoK, and in addition to the vast sums spent on connecting low-revenue electricity customers, the grid is becoming harder to manage and performance on the edges is bound to suffer. Other approaches to electrification should be considered; in areas with dense populations, grid-disconnected minigrids either operated by the utility or by a private entity may be a better solution. For customers not likely to consume very much electricity, low-cost solar home systems may be more cost-effective while still meeting customer needs.

While alternative means for electrification have many potential benefits, it is also important to understand the limitations of those alternatives. While there is significant excitement for solar home systems, particularly from many investors and from the USAID Power Africa program, these systems are by no means a panacea for the problem of limited electricity access. Figure 13 shows the power consumptions of common residential and productive use appliances and also plots the solar panel size for two prominent solar home systems in Kenya from M-KOPA 7]. It is important to note that while these M-KOPA systems can accommodate the electricity demand for low-consumption households, their high cost makes them uneconomical as customers move up the appliance ladder. Table 2 presents the cost of M-KOPA's two primary solar home system kits: the M-KOPA V, which includes an 8W solar panel and appliances; and the M-KOPA 400 , which includes the same appliances plus a television. We can see that adding a single larger appliance multiplies the overall cost of the kit by $2.5 \mathrm{x}$, and pushes the price to a level that is inaccessible for much of the rural population. Higher-consumption appliances - and especially those for productive uses like refrigerators, sewing machines, milling machines, and welding equipment - will remain beyond the capabilities of a solar home system for some time. Also from Figure 13, we can see the power supply of one of the larger photovoltaic panels available for the global residential rooftop market; this shows that the limitation for solar home systems to support larger appliances is not the power supply of the PV panel but in fact, the high cost of the battery needed to support the appliances. Though there are excellent ongoing efforts to build low-consumption appliances for off-grid markets, the economics for solar home systems to provide electricity supply for productive uses will remain challenging for the foreseeable future.

For minigrids, there is substantial challenge involved in obtaining the higher 
Figure 13. Power consumption ranges for typical appliances compared against panel sizes for solar home systems and a large residential rooftop installation. Note that power consumption figures provided are approximate.

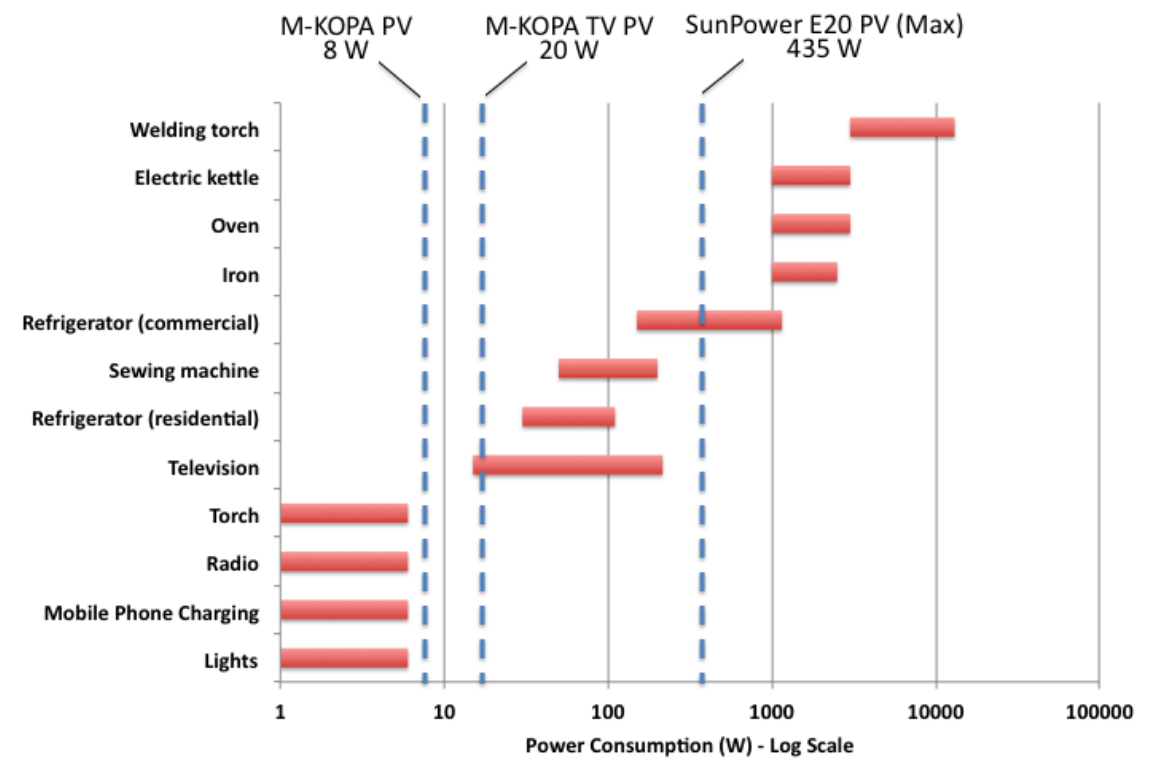

Table 2. Total costs to the customer for purchasing two different M-KOPA solar kits. Conversion rate used is $103.8 \mathrm{Ksh} / \mathrm{USD}$.

\begin{tabular}{|c|cccc|}
\hline SHS Kit & $\begin{array}{c}\text { Upfront } \\
\text { Payment }\end{array}$ & $\begin{array}{c}\text { Daily Payment } \\
\text { (For a year) }\end{array}$ & $\begin{array}{c}\text { Total } \\
\text { (KSh) }\end{array}$ & $\begin{array}{c}\text { Total } \\
\text { (USD) }\end{array}$ \\
\hline $\begin{array}{c}\text { M-KOPA V } \\
\text { Lights/Torch/ } \\
\text { PhoneCharger/Radio }\end{array}$ & $2999 \mathrm{Ksh}$ & $50 \mathrm{Ksh}$ & $21249 \mathrm{Ksh}$ & $\$ 205$ \\
\hline $\begin{array}{c}\text { M-KOPA 400 } \\
\text { Same as M-KOPA } \\
\text { V + Television }\end{array}$ & $7999 \mathrm{Ksh}$ & $125 \mathrm{Ksh}$ & $53624 \mathrm{Ksh}$ & $\$ 515$ \\
\hline
\end{tabular}


capital needed to finance the significant upfront investment. Though there is effort to better quantify the financing risk for private investors [22, 23], other challenges for minigrids include unsettled or unfavorable national policy, lack of clarity around centralized grid expansion plans, and a dearth of ideal yet still unelectrified sites. In total, these hinder the likelihood of substantial minigrid success in Kenya.

Thus, with an understanding of the advantages and limitations of grid electricity, minigrids, and solar home systems, what is the remaining challenge for electricity system planners? At present, we argue that the available data and tools are insufficient to properly target the lowest-cost systems to meet the needs of individual consumers. As kilowatt-hours are fungible, consumers generally do not place much value in the source of their electricity, but much more in the cost and reliability. The GoK, Kenya Power, multilateral donors, and investors are currently engaged in a competition to meet electricity needs in Kenya that pits different technologies mostly competing for the same set of mid-market consumer ${ }^{3}$, rather than acknowledging the inherent strengths and weaknesses of each technology and meeting the needs of particular consumers in an integrated fashion.

Typically, this results in individual organizations specializing in a particular technology - be it grid, minigrid, or solar home system - and applying it universally. While Kenya Power is engaging in the Kenya Off-Grid Solar Access Project (KOSAP) [17. to deploy minigrids in low-density regions in the North, Northeast, and Coast, we argue that a regional solution is insufficient technologies should not be chosen per-region, but should fit the individuals and communities where they can provide the lowest-cost, sufficient electricity supply and distribution. At the most urgent level, utilities should consider solar home systems for those customers whose expected consumption merits that connection; the cost of grid connections for these customers threatens the entire utility business model and its ability to meet future needs. Additionally, aggressively growing the electricity grid without consideration of likely electricity consumption is likely to waste a lot of money on unnecessary capital expenditures and, in the medium to long-term, result in higher operating costs, further straining the utility. The ecosystem requires better data and tools to find the lowest-cost systems to meet present and future consumption among electricity customers.

Last, to foster collaboration and integration, it is necessary to refine the policy regime towards distributed generation. This will encourage broader participation and cooperation among private and public entities engaging on improving electricity system access and reliability. In collaboration with the World Bank, the Ministry of Energy and Petroleum of Kenya has taken a strong first step towards collecting, standardizing, and publicizing more sources of energy and electricity data as part of KOSAP. Some remaining issues include:

- At present, minigrid and solar home system companies have little insight into the expansion plans of the utility that present enormous risk to dis-

\footnotetext{
${ }^{3}$ For example, roughly $95 \%$ of M-KOPA's customers in Kenya are within range of grid access.
} 
tributed electricity investments. Better planning and perhaps the provisioning of leases on providing electricity supply in specific areas could prove beneficial to electrification goals.

- There is limited to zero written policy for incorporating distributed assets into the centralized grid, forcing minigrid providers to incur too much risk that their assets will be stranded.

- While not currently in place in Kenya, any policy that requires minigrid providers to sell electricity at a universal national tariff but does not provide sufficient subsidies is effectively a nonstarter for any minigrid company to invest.

In total, the challenge of more cost-effectively matching infrastructure to consumer electricity needs requires honest assessments of electricity consumption, a clearer appraisal of regional developments in electricity, and more flexible deployments of the different technologies and business models available and emerging.

\section{Conclusion}

Developments in technology, emergent new business models, and increasingly smarter investments in electricity provision make the present an exciting era for electricity systems the world over. Kenya is at the forefront of these developments, massively investing in innovative methods for providing electricity access, and provides a valuable case study for understanding the factors driving development, investment, and success in the electricity sector. This paper provided background and a data-driven assessment of the most substantial challenges that Kenya faces today in improving its ability to provide plentiful, low-cost electricity as a means to improve the lives and livelihoods of the Kenyan people. We believe that the lessons learned in Kenya can serve as critical guideposts for providing universal and sustainable energy access for all.

\section{References}

[1] Demand setback now puts Kenya's mega power plan on the back burner. The Standard, 9 January 2017. Available: Www.standardmedia.co.ke/business/article/2000229172/ demand-setback-now-puts-kenya-s-mega-power-plan-on-the-back-burner/.

[2] Garden City Mall Solar PV Deployment. www.solarafrica.com/ portfolio/garden-city-mall/.

[3] How power line meant to bring down cost of electricity will push up bills. The Standard, 22 October 2017. Available: www.standardmedia.co.ke/business/article/2001258005/ kenya-pays-sh5-7-billion-penalty-for-turkana-wind-power-line-delay/ 
[4] Kenya National Bureau of Statistics. www.knbs.or.ke/.

[5] Why Build Kenya?s First Coal Plant? Hint: Think China. The Standard, 27 February 2018. Available: https://www.nytimes.com/2018/02/ 27/climate/coal-kenya-china-power.html.

[6] Lying to the President: How Kenya Power managers cooked Last Mile connection figures. The Standard, 19 March 2017. Available: $\quad$ www.standardmedia.co.ke/business/article/2001233193/ shocking-kenya-power-details-of-fake-meter-activations-to-please-president-uhuru/.

[7] M-KOPA Solar. www.m-kopa.com/.

[8] M. Aklin, P. Bayer, S. Harish, and J. Urpelainen. Does basic energy access generate socio-economic benefits? a field experiment with off-grid solar power in india. Science Advances, 3:1-8, 2017.

[9] I. Bisaga, N. Puzniak-Holford, A. Grealish, C. Baker-Brian, and P. Parikh. Scalable off-grid energy services enabled by IoT: A case study of BBOXX SMART Solar. Energy Policy, 109:199-207, 2017.

[10] D. Chaplin, A. Mamun, A. Protik, J. Schurrer, D. Vohra, K. Bos, H. Burak, L. Meyer, A. Dumitrescu, C. Ksoll, and T. Cook. Grid Electricity Expansion in Tanzania by MCC: Findings from a Rigorous Impact Evaluation, Final Report. 2017.

[11] T. Dinkelman. The effects of rural electrification on employment: New evidence from South Africa. American Economic Review, 101:3078-3108, 2011.

[12] A. Eberhard, K. Gratwick, E. Morella, and P. Antmann. Independent Power Projects in Sub-Saharan Africa: Lessons from Five Key Countries. World Bank, 2016.

[13] Fichtner Management Counsulting AG. Consultancy services for development of electricity connection policy and draft regulations. 2014.

[14] S. Fobi, V. Deshpande, S. Ondiek, V. Modi, and J. Taneja. A longitudinal study of electricity consumption growth in kenya. In submission, 2017.

[15] B. K. Jack and G. Smith. Charging ahead: Prepaid electricity metering in south africa. National Bureau of Economic Research Working Papers, 2016.

[16] Kenya Power. Kenya power annual report and financial statements. 2016.

[17] Kenya Power. Kenya Off-Grid Solar Access Project (KOSAP), 2017.

[18] M. Kojima and C. Trimble. Making power affordable for africa and viable for its utilities. World Bank, 2016. 
[19] K. Lee, E. Miguel, and C. Wolfram. Appliance ownership and aspirations among electric grid and home solar households in rural kenya. American Economic Review, 2016.

[20] K. Lee, E. Miguel, and C. Wolfram. Experimental evidence on the demand for and costs of rural electrification. National Bureau of Economic Research Working Papers, 2016.

[21] L. Parshall, D. Pillai, S. Mohan, A. Sanoh, and V. Modi. National electricity planning in settings with low pre-existing grid coverage: Development of a spatial model and case study of kenya. Energy Policy, 37:2395-2410, 2009.

[22] N. J. Williams, P. Jaramillo, and J. Taneja. An investment risk assessment of microgrid utilities for rural electrification using the stochastic technoeconomic microgrid model: A case study in rwanda. Energy for Sustainable Development, 42:87-96, 2018.

[23] N. J. Williams, P. Jaramillo, J. Taneja, and T. S. Ustun. Enabling private sector investment in microgrid-based rural electrification in developing countries: A review. Renewable and Sustainable Energy Reviews, 52:12681281, 2015. 